\title{
Urgences
}

\section{Roselyne Grand-Maison et Michel Cayouette, Où est le trou du rocher Percé ?, Sherbrooke, Naaman, coll. " Jeunesse ", 1981, 32}

p.

\section{Gilbert Dupuis}

Numéro 4, 2e trimestre 1982

URI : https://id.erudit.org/iderudit/025067ar

DOI : https://doi.org/10.7202/025067ar

Aller au sommaire du numéro

\section{Éditeur(s)}

Urgences

\section{ISSN}

0226-9554 (imprimé)

1927-3924 (numérique)

Découvrir la revue

Citer ce compte rendu

Dupuis, G. (1982). Compte rendu de [Roselyne Grand-Maison et Michel Cayouette, Où est le trou du rocher Percé ?, Sherbrooke, Naaman, coll. " Jeunesse ", 1981, 32 p.] Urgences, (4), 89-91. https://doi.org/10.7202/025067ar d'utilisation que vous pouvez consulter en ligne.

https://apropos.erudit.org/fr/usagers/politique-dutilisation/ 
"s'enfant-prodigue", "se pilote automatique", se mêle de "comprenure", d" "achalerie", de quand "le monde "bière"" et que "ça snorraude"!)

Me plaisent ces rouges perspectives du Langage. Dans I'absolu... lisiblement!

Lise Lessard

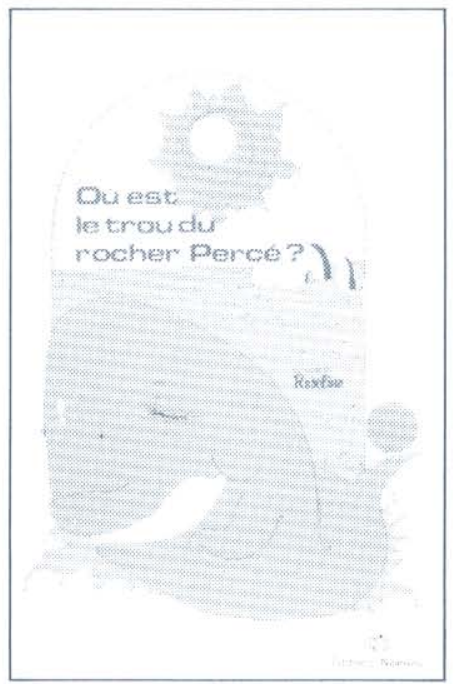

OU் EST LE TROU DU ROCHER PERCÉ?, Roselyne GrandMaison et Michel Cayouette, Naaman, 1981.

Écrire pour les enfants n'est pas une entreprise aisée. II suffit à quiconque de s'y aventurer pour s'en convaincre. Ne faut-il pas pour atteindre l'univers de l'enfant (je ne dis pas le monde enfantin), franchir l'espace, trouver le point de vue, l'angle, l'ouverture, ne faut-il pas remonter le temps, prendre du recul (j'aurais pu dire de l'avance), identifier ses conditionnements, se (re)faire une sorte de candeur consciente et/ou de conscience candide. La problématique de l'écriture du conte pour enfants ne réside-t-elle pas dans la réalisation d'une fusion équilibrée du plausible et du merveilleux au fil d'une narration exploitant toutes 
les ressources du langage pour le plus grand pouvoir évocateur du texte?

C'est-à-dire que l'eau la plus pure nous apparaît trouble autravers d'un verre déformant; c'est-à-dire que le meilleur fil conducteur doit être (trans)porté par le langage et non pas développé malgré lui. Voilà quelques prémisses qui veulent signifier la double importance du meuble et de l'outil, de l'histoire et de la narration, du contenu et du contenant quand on s'intéresse à la communication littéraire.

Le conte illustré s'apparente au cinéma par le découpage d'une histoire (scénario) en épisodes (séquences) illustrés (plans). Dans OU் EST LE TROU DU ROCHER PERCÉ? (1), la scène principale montre une baleine coincée dans le trou du célèbre rocher. II n'y a pas pléthore de contes pour enfants dont le décor soit planté dans notre région; il faut donc savoir gré à l'auteur pour son choix de Percé comme lieu de tournage. Le petit livre de Roselyne Grand-Maison et Michel Cayouette est divisé en douze séquences dont l'enchaînement répond à un ordre logique rigoureux. Bravo pour la plausibilité. Les illustrations en trois couleurs unies sont stylisées juste ce qu'il faut pour rendre l'essentiel de chaque épisode.

Par ailleurs, le texte du conte pour enfants ne doit-il pas faire appel aux images plutôt qu'aux concepts, ne doit-il pas viser l'économie et l'efficacité? On aurait préféré des tournures moins abstraites que "le soleil a décidé (p. 9)... Thimothée la baleine a décidé (p. 12)... la baleine décide ( $p$. 15)... pense Thimothée ( $p$. 16)... pense Thimothée, qui se console (...) à l'idée" (p. 28)...; il aurait été facile de déceler un hiatus aussi malgracieux que "le trou où une..." (p. 22).

Lu sous un autre angle, OU் EST LE TROU DU ROCHER PERCÉ? nous fait voir la singularisation de quatre personnages masculins (M. Lapierre, Éric, M. le maire et le directeur des services aux incendies de forêts) et de deux personnages féminins (Louise et la vieille dame); il faut reconnaître toutefois que la petite fille et le petit garçon jouent des rôles d'importance équivalente. 
Les impressions de lecture que la chûte du conte suggère vont de la force de l'humaine solidarité jusqu'à l'amour des bêtes en passant par le goût de l'aventure. Malgré ses maladresses langagières, OU் EST LE TROU DU ROCHER PERCÉ? soulève I'intérêt par l'originalité de la scène-argument et par le fait du déroulement de I'histoire dans notre région. II faut par ailleurs regretter que l'éditeur n'ait consenti davantage d'efforts pour rendre attrayant le livre-objet au niveau de la couverture, du format et des couleurs.

Pour être plus complet, ce commentaire aurait pu comprendre quelques réactions d'enfants lecteurs... mais ce n'est pas la première fois que nous faisons à nos enfants le coup du train électrique...

Gilbert Dupuis

(1) OUं EST LE TROU DU ROCHER PERCÉ?, Roselyne GrandMaison. Illustrations: I'auteur et Michel Cayouette. Éditions Naaman, collection Jeunesse, 32 pages brochées, Sherbrooke, 1981.

WESTERNITÉ, Jean-Marc Cormier, Les Ėditions Passages, 1981.

"La robine littéraire" qui ouvre le recueil de poèmes de JeanMarc Cormier constitue une prise de position sans équivoque:

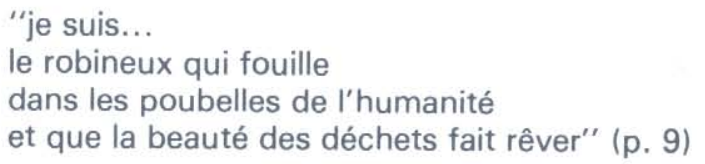

Ces quelques vers révèlent les deux principaux aspects de la thématique du recueil: le monde corrompu, défiguré et réducteur d'esprit dans lequel chaque être humain cherche sa lumière, son unité, et en même temps, la fonction du poète qui est de crier cette quête inouïe de bonheur et d'amour qui s'accomplit dans la nuit et la boue. 